\title{
Ormosanine improves neuronal functions in spinal cord-injured rats by blocking peroxynitrite/calpain activity
}

https://doi.org/10.1515/tnsci-2020-0106

received March 27, 2020; accepted April 27, 2020

\begin{abstract}
The present study was performed to evaluate the effects of ormosanine against spinal cord injury (SCI) in rats and to examine the possible molecular mechanism of action. SCI was induced using an impactor device, and rats were treated with ormosanine 10,50 or $100 \mathrm{mg} / \mathrm{kg}$, p.o., for 10 days after induction of SCI. The effect of ormosanine on SCI was determined by estimating neurological functions and cytokines and parameters of oxidative stress level were estimated in SCI rats. Quantitative reverse transcription polymerase chain reaction, Western blotting analysis and histopathological study were performed on spinal tissue of SCI rats. The data suggested that treatment with ormosanine reversed the alterations of neurological function in SCI rats. Moreover, the levels of cytokines, oxidative stress and reactive oxygen species production were reduced in the ormosanine treatment group compared to the SCI group. The levels of calpain and neuronal nitric oxide synthase activity were significantly reduced in the spinal tissue of the ormosanine treatment group compared to the SCI group. Moreover, ormosanine treatment reduced the percentage of viable neurons in the spinal tissue of SCI rats. In conclusion, the results of this study showed that ormosanine treatment had a protective effect against neuronal injury in spinal cord-injured rats by regulating the peroxynitrite/calpain activity.
\end{abstract}

Keywords: ormosanine, spinal cord injury, peroxynitrite, calpain, inflammation

\footnotetext{
* Corresponding author: Yajun Liu, Beijing Jishuitan Hospital Search for articles by this author in MEDLINE $®$, Beijing, China, e-mail: IsaacSharonyWoBb@yahoo.com

Yan An, Jianing Li, Mingxing Fan: Department Of Spine Surgery, Beijing Jishuitan Hospital, Beijing 100035, China
}

\section{Introduction}

Spinal cord injury (SCI) is a spinal cord damage that causes loss of function, such as feeling or mobility, due to increased production of several toxic metabolites [1]. The prevalence of SCI is increasing around the world, and it is a major health care issue with a significant socioeconomic impact [2]. SCI occurs due to ischemic, toxic and traumatic injury and further cellular damage or death is divided into two types, i.e., $\mathrm{I}^{\mathrm{ry}}$ and $\mathrm{II}^{\mathrm{ry}}$ SCI [3]. Several factors and pathways, i.e., excitotoxicity, redox and inflammatory mediators, are involved in the development of secondary injury leading to activation of neuronal apoptosis [4]. Activation of microglia stimulates the release of cytokines and reactive oxygen species (ROS), which contribute to the development of secondary injury in SCI [5]. Reduction of microglial activation ameliorates neuronal cell apoptosis, oxidative stress and inflammation in SCI [6]. Moreover, the bioavailability of nitric oxide (NO) is reduced in SCI, leading to overactivity of neuronal nitric oxide synthase (nNOS), which occurs due to excessive calcium overload [7]. This elevation of nNOS activity enhances the production of peroxynitrite, and activation of calpain occurs due to its overproduction, which contributes to the development of neuronal injury [8]. Inhibition of nNOS activity has a protective effect against neuronal injury. A number of drugs and surgical procedures are used for the management of SCI [9]. However, their effects are limited, and new drugs for the treatment of SCI are required.

Ormosanine is a pentacyclic alkaloid isolated from Akebia quinata (AQ) [10]. AQ, which is widely available in several parts of Asia, including Korea, Japan and China, has been reported to possess antibacterial, antioxidant, antidiuretic, anti-inflammatory and analgesic activities [11]. AQ has also been reported to contain several secondary metabolites such as chlorogenic acid, isochlorogenic acid $\mathrm{A}$, isochlorogenic acid $\mathrm{C}$, triterpenoid saponins and ormosanine, which has shown potential 
medicinal properties [12]. Ormosanine is one of the major chemical components of $\mathrm{AQ}$, and it has also been reported to have antimalarial, analgesic, sedative, hypnotic and liver protective activities [13-15]. The present study was performed to evaluate the protective effects of ormosanine against secondary neuronal injury in SCI.

\section{Materials and methods}

\subsection{Animals}

Male Sprague-Dawley rats weighing $250-300 \mathrm{~g}$ were kept under a 12-h light/dark cycle at $60 \pm 5 \%$ humidity and a temperature of $24 \pm 3^{\circ} \mathrm{C}$.

Ethical approval: The research related to animal use has been complied with all the relevant national regulations and institutional policies for the care and use of animals. The protocols used were approved by the Institutional Animal Care Committee of Beijing Jishuitan Hospital, China (IAEC/BJH/2018/03), and the animals were handled as per the Association for the Assessment and Accreditation of Laboratory Animal Care International (AAALAC) guidelines.

\subsection{Chemicals}

Ormosanine was provided by Kunming Institute of Botany, China. Enzyme-linked immunosorbent assay (ELISA) kits were purchased from R\&D Systems (Minneapolis, MN, USA). Antibodies used in Western blotting analysis were obtained from Thermo Fisher Scientific (Wilmington, DE, USA).

\subsection{Experimental}

Following anaesthesia by intraperitoneal administration of $10 \mathrm{mg} / \mathrm{kg}$ xylazine and $90 \mathrm{mg} / \mathrm{kg}$ ketamine, the animals were placed on a stereotaxic apparatus. The spinal cord was exposed at the level of the thoracic vertebrae (T9-T10), and laminectomy was performed after making a dorsal median incision. SCI was induced as reported previously using a computer-operated impactor device with a contusion time of $85 \mathrm{~ms}$, impact velocity of $1.5 \mathrm{~m} / \mathrm{s}$ and tissue deformation of $2 \mathrm{~mm}$. The incision was then closed using sutures. Fifty animals were divided into five different groups, with ten animals in each group: untreated control group (positive control group); SCI group (negative control group); and ormosanine 10,50 and $100 \mathrm{mg} / \mathrm{kg}$ groups, which received ormosanine at doses of 10,50 and $100 \mathrm{mg} / \mathrm{kg}$, p.o., respectively, for 10 days.

\subsection{Estimation of sensory function and motor behaviour}

Locomotor activity was estimated by the open field test as reported previously [16]. Animals were allowed to move freely for $20 \mathrm{~min}$ in front of a light source, and the locomotor activity was estimated from the total number of circuit breaks. The Basso, Beattie and Bresnahan (BBB) score was estimated for all groups throughout the experimental period.

A von Frey plastic chamber was used to estimate mechanical allodynia as reported previously [17]. All animals were habituated to the test environment by placing them in the chamber for $2 \mathrm{~h}$. An aesthesiometer was used to determine nociception by measuring the paw pressure threshold.

\subsection{Estimation of cytokines}

The serum levels of the inflammatory mediators, interleukin (IL)-1 $\beta$, IL-6, nuclear factor kappa B (NF-kB) and tumour necrosis factor (TNF)- $\alpha$, were determined by ELISA using commercial kits in accordance with the manufacturer's protocols (R\&D Systems).

\subsection{Estimation of ROS}

MitoSOX red mitochondrial superoxide indicator was used to estimate the levels of ROS in the intestinal tissues. Briefly, tissue homogenates were stained at $37^{\circ} \mathrm{C}$ in the dark for $30 \mathrm{~min}$ with $5 \mu \mathrm{M}$ MitoSOX red. A fluorescent plate reader was used to estimate the intracellular ROS levels at excitation and emission wavelengths of 510 and $580 \mathrm{~nm}$, respectively.

\subsection{Determination of oxidative stress}

Malondialdehyde (MDA) and superoxide dismutase (SOD) activities were estimated in intestinal tissues using ELISA kits according to the manufacturer's instructions (R\&D Systems). 


\subsection{Estimation of nitric oxide synthase activity}

A nitric oxide synthase (NOS) assay kit was used to estimate the activity of NOS in the SCI tissues by determining the formation of $\mathrm{L}-[4,5-3 H]$ citrulline from $\mathrm{L}-[4,5-3 H]$ arginine. The total activity of constitutive NOS was estimated by subtracting the calcium-independent activity of NOS from the total NOS activity in $\mathrm{pmol} / \mathrm{mg}$ protein/min.

\subsection{Calpain activity assay}

A calpain activity assay kit was used to estimate the activity of calpain in accordance with the manufacturer's instructions. Each animal's spinal tissue homogenate was incubated with reaction buffer and calpain substrate, and fluorometric analysis was performed to estimate cleavage of the substrate by calpain.

\subsection{Quantitative reverse transcription polymerase chain reaction}

Trizol reagent was used to isolate the total RNA from kidney tissues in accordance with the manufacturer's instructions. A reverse transcription kit was used to reverse-transcribe cDNA from RNA in accordance with the manufacturer's instructions. An ABI Prism 7500 system (Applied Biosystems, Foster City, CA, USA) was used with a SYBR green/fluorescein qPCR Master Mix kit (Thermo Fisher Scientific) with the following conditions: $50^{\circ} \mathrm{C}$ for $2 \mathrm{~min} ; 95^{\circ} \mathrm{C}$ for $10 \mathrm{~min}$; followed by 40 cycles at $95^{\circ} \mathrm{C}$ for $30 \mathrm{~s}$ and $60^{\circ} \mathrm{C}$ for $30 \mathrm{~s}$. The resulting data were analysed using the comparative $\mathrm{Ct}$ method $\left(2^{-\Delta \mathrm{CCt}}\right)$.

\subsection{Primers (forward, reverse)}

The primers used in this study are as follows: Caspase-3: 5'GTGGAACTGACGATGATATGGC-3'， 5'-CGCAAAGTGACTGGA TGAACC-3'; NF-кB: 5'-GAGCAAATGGTGAAGGAG-3', 5'-TCT GGAAGTTGAGGAAGG-3'; Bax: 5'-CGGCGAATTGGAGATGA ACTGG-3， 5'-CTAGCAAAGTAGAAGAGGGCAACC-3'; Bcl2: 5'-TGTGGATGACTGACTACCTGAACC-3', 5'-CAGCCAGGAGA AATCAAACAGAGG-3'; and $\beta$-Actin: $5^{\prime}$-AGTGTGACGTTGACATCCGTAA-3', 5'-GGACAGTGAGGCCAGGATAGA-3'.

\subsection{Western blotting analysis}

Western blotting analysis was performed to assess phosphoextracellular signal-regulated kinase (p-ERK), extracellular signal-regulated kinase (ERK), nNOS, phospho-nNOS (p-nNOS), calpain 1, calpain 2 and $\beta$-actin protein expression in the spinal cord tissue homogenate. A BCA assay kit (Thermo Fisher Scientific) was used to quantify the protein in the tissue homogenate, and 10\% SDS-PAGE was performed to separate the proteins, which were electroblotted onto nitrocellulose membranes. Subsequently, the membranes were blocked with a blocking solution containing $5 \%$ non-fat milk and then incubated in blocking buffer with the following primary antibodies overnight at $4^{\circ} \mathrm{C}$ : p-ERK (1:100; Santa Cruz Biotechnology, Santa Cruz, CA, USA), ERK (1:100; Santa Cruz Biotechnology), nNOS (1:100; Santa Cruz Biotechnology), p-nNOS (1:100; Santa Cruz Biotechnology), calpain 1 (1:200; Cell Signaling Technology, Danvers, MA, USA), calpain 2 (1:200; Cell Signaling Technology) and $\beta$-actin (1:100; Santa Cruz Biotechnology). Later goat secondary antibody conjugated with horseradish peroxidase was added to the blocking buffer, and a chemiluminescence kit was used to detect the proteins.

\subsection{Nissl staining}

Each animal's spinal cord tissues were isolated, dehydrated and embedded in paraffin. The isolated spinal cord tissue was cut into $10 \mu \mathrm{m}$ thick sections using a microtome and stained with $1 \%$ cresyl violet. Image Pro Plus 6.0 software (Media Cybernetics, Silver Spring, MD, USA) was used to estimate the number of Nissl stainpositive neuronal cells.

\subsection{Statistical analyses}

All data are expressed as mean \pm standard error of the mean (SEM; $n=10)$. Statistical analyses were performed by one-way analysis of variance. Post hoc comparisons were carried out with Dunnett's test using GraphPad Prism software (ver. 6.1; GraphPad Software, Inc., San Diego, CA, USA). In all analyses, $P<0.05$ was taken to indicate statistical significance.

\section{Results}

\subsection{Ormosanine ameliorates the alterations in neurological function in $\mathrm{SCl}$ rats}

The effects of ormosanine on the neurological function scores were determined by examining locomotor function 


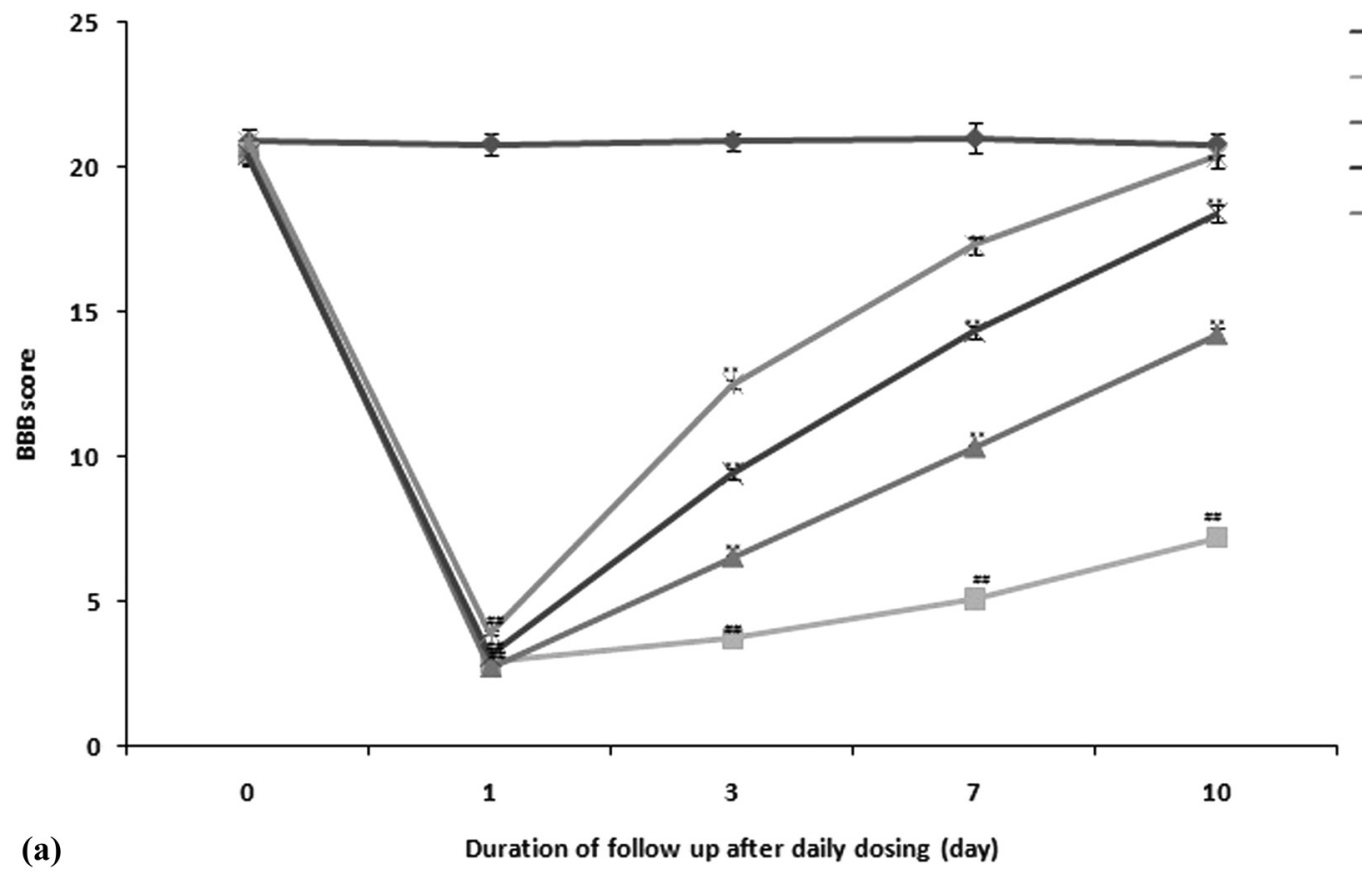

$$
\begin{aligned}
& \multimap \text { Control } \\
& - \text { SI } \\
& - \text { Ormosanine } 10 \mathrm{mg} / \mathrm{kg} \\
& \nVdash \text { Ormosanine } 50 \mathrm{mg} / \mathrm{kg} \\
& \longleftarrow \text { Ormosanine } 100 \mathrm{mg} / \mathrm{kg}
\end{aligned}
$$

(a)

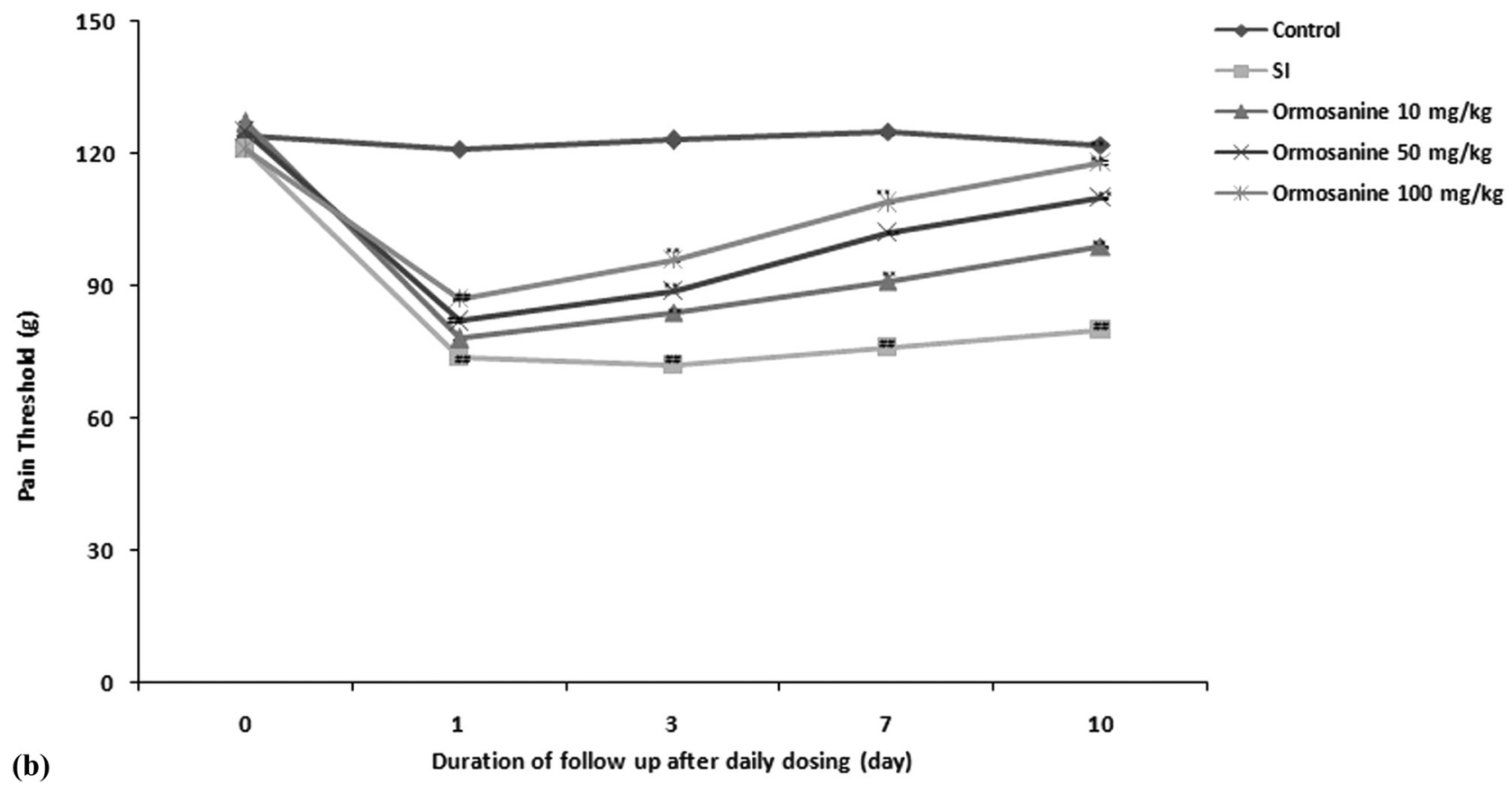

Figure 1: Ormosanine ameliorates the changes in neurological function scores in SCl rats. (a) Locomotor function estimated by the BBB score. (b) The pain threshold was examined to estimate neuropathic pain. Mean \pm SEM $(n=10) .{ }^{\# \#} P<0.01$ vs control group; ${ }^{\star \star P}<0.01$ vs $\mathrm{SCl}$ group.

and pain threshold in SCI rats (Figure 1a and b). Locomotor function was examined based on the BBB score in each animal. The SCI group showed significantly reduced BBB scores compared to the control group on days 1, 3, 7 and 10 of the experimental period. However, treatment with ormosanine reversed the alteration in the BBB score in SCI rats in a dose-dependent manner (Figure 1a). Pain threshold was significantly reduced in the SCI group compared to the control group. Treatment with ormosanine improved the pain threshold in a dose- 


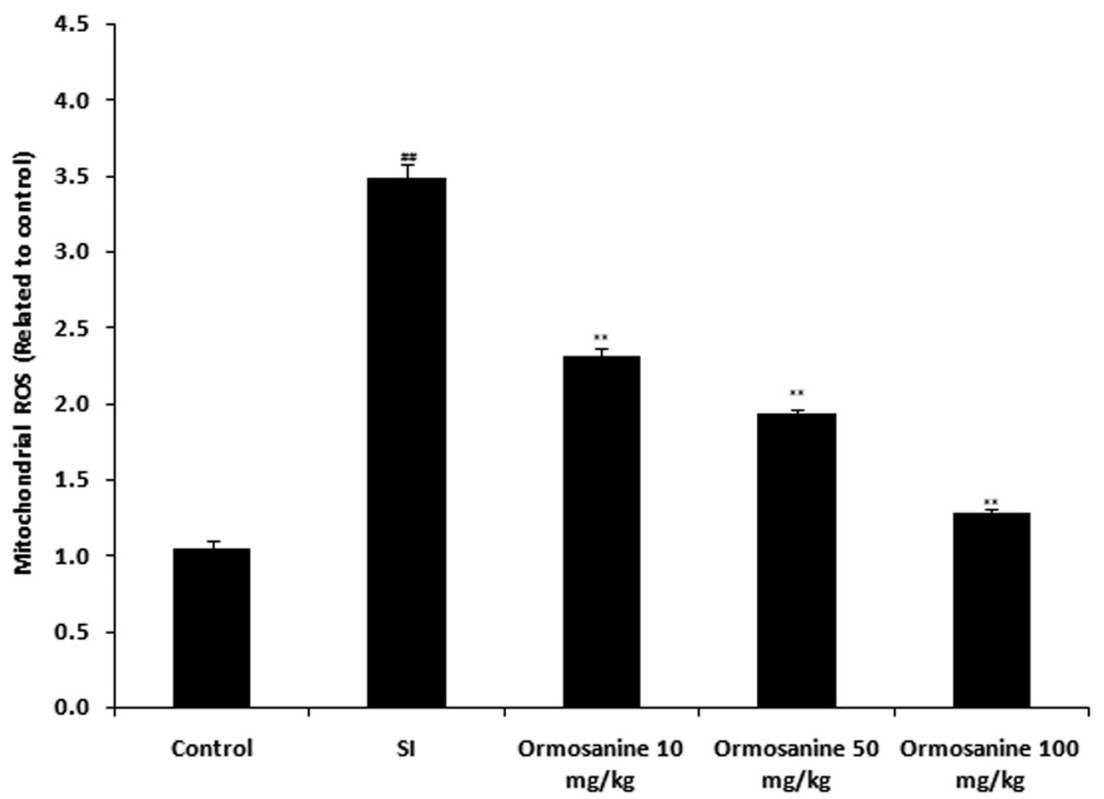

Figure 2: Ormosanine reduces the production of ROS in the spinal tissue of $\mathrm{SCI}$ rats. Mean $\pm \mathrm{SEM}(n=10)$. ${ }^{\# \#} P<0.01$ vs control group; $\star \star P<0.01$ vs $\mathrm{SCl}$ group.

dependent manner compared to the SCI group throughout the experimental period (Figure 1b).

\subsection{Ormosanine ameliorates the changes in ROS production in the spinal tissue of $\mathrm{SCl}$ rats}

Production of mitochondrial ROS was detected in the spinal cord tissue homogenate of ormosanine-treated SCI rats, as shown in Figure 2. Mitochondrial ROS production was significantly higher in the spinal tissue of the SCI group compared to that in the control group. The production of mitochondrial ROS was reduced by ormosanine treatment in a dose-dependent manner compared to the SCI group.

\subsection{Ormosanine ameliorates the changes in inflammatory cytokine levels in the spinal tissue of $\mathrm{SCl}$ rats}

The levels of cytokines were estimated in the spinal tissue of ormosanine-treated SCI rats, as shown in Figure 3. The serum cytokine levels were increased in the SCI group compared to the control group. Treatment with ormosanine at different doses ameliorated these changes in serum cytokine levels in SCI rats in a dose-dependent manner.

\subsection{Ormosanine ameliorates the changes in the parameters of oxidative stress in the spinal tissue of $\mathrm{SCl}$ rats}

Parameters of oxidative stress were determined in the spinal tissue of ormosanine-treated SCI rats, as shown in Figure 4. The SOD activity was reduced, whereas the MDA activity was increased in the spinal tissue of the SCI group compared to the control group. However, the ormosanine treatment groups showed increases in the SOD activity and reductions in the MDA activity in the spinal tissue compared to the SCI group.

\subsection{Ormosanine ameliorates the changes in calpain and NOS activity in the spinal tissue of $\mathrm{SCl}$ rats}

The effects of ormosanine treatment on the activities of calpain and nNOS in the spinal tissue of SCI rats were examined. The levels of calpain and nNOS activity were significantly increased in the spinal tissue of the SCI group compared to the control group. However, treatment with ormosanine at different doses ameliorated these changes in calpain and nNOS activity in the spinal tissue of SCI rats in a dose-dependent manner (Figure 5). 


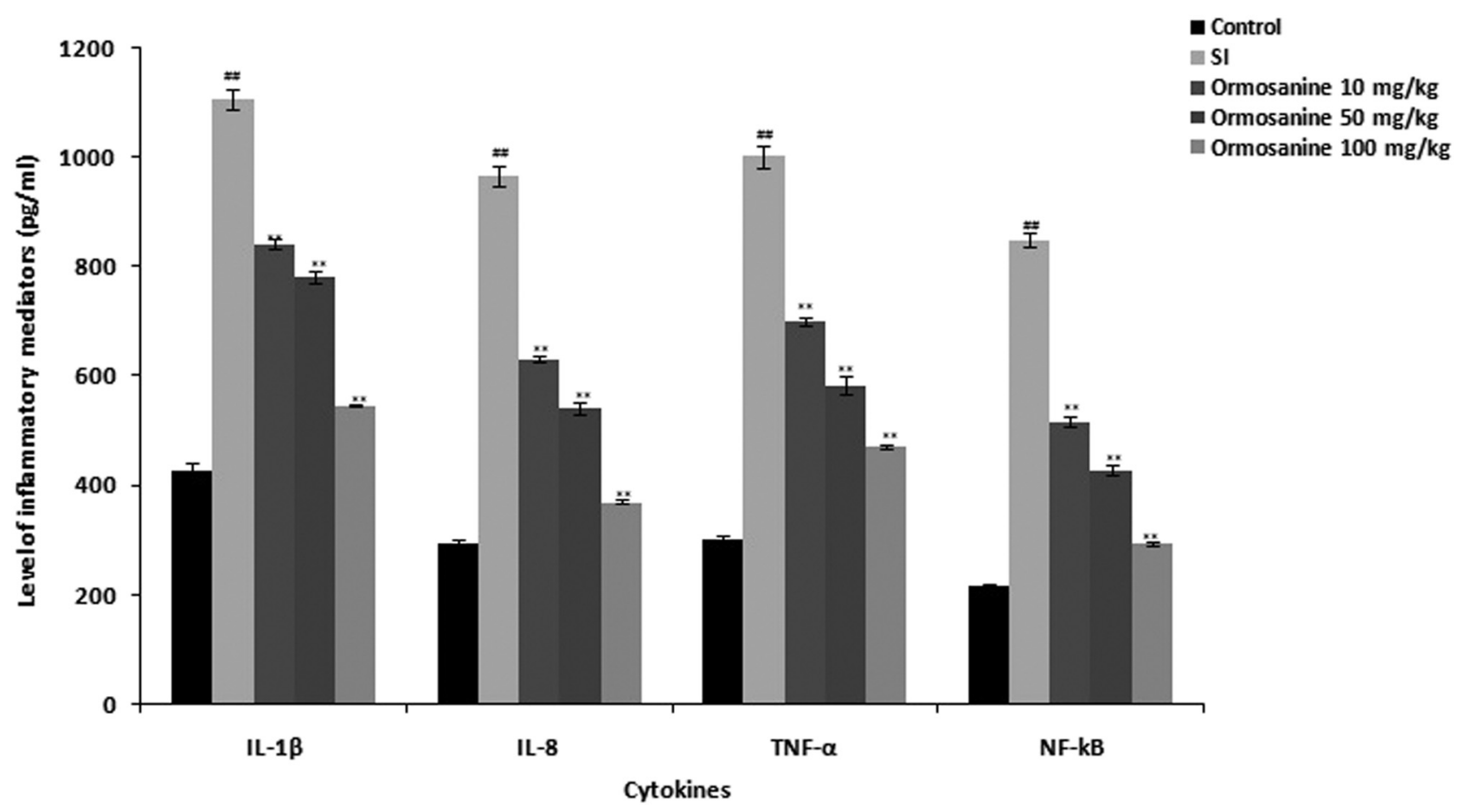

Figure 3: Ormosanine reduces inflammatory cytokine levels in the spinal tissue of SCI rats. Mean $\pm \mathrm{SEM}(n=10) .{ }^{\# \#} P<0.01$ vs control group; ${ }^{* \star} P<0.01$ vs $\mathrm{SCl}$ group.


Figure 4: Ormosanine ameliorates the changes in parameters of oxidative stress in the spinal tissue of SCI rats. Mean \pm SEM $(n=10)$. ${ }^{\# \#} P<0.01$ vs control group; ${ }^{\star \star} P<0.01$ vs $\mathrm{SCl}$ group.

\subsection{Ormosanine ameliorates the changes in NF-KB, Caspase-3, Bax and Bcl2 mRNA expression in the spinal tissue of $\mathrm{SCl}$ rats}

Figure 6 shows the effects of ormosanine on NF$\kappa B$, Caspase-3, Bax and Bcl2 mRNA expression in the spinal tissue of SCI rats. The relative levels of NF- $\kappa B$,
Caspase- 3 and Bax mRNA expression were significantly increased, and expression of Bcl-2 was significantly reduced in the spinal tissue of the SCI group compared to the control group. Treatment with ormosanine ameliorated the alterations in NF- $\mathrm{kB}$, Caspase-3, Bax and Bcl2 mRNA expression in the spinal tissue of SCI rats. 

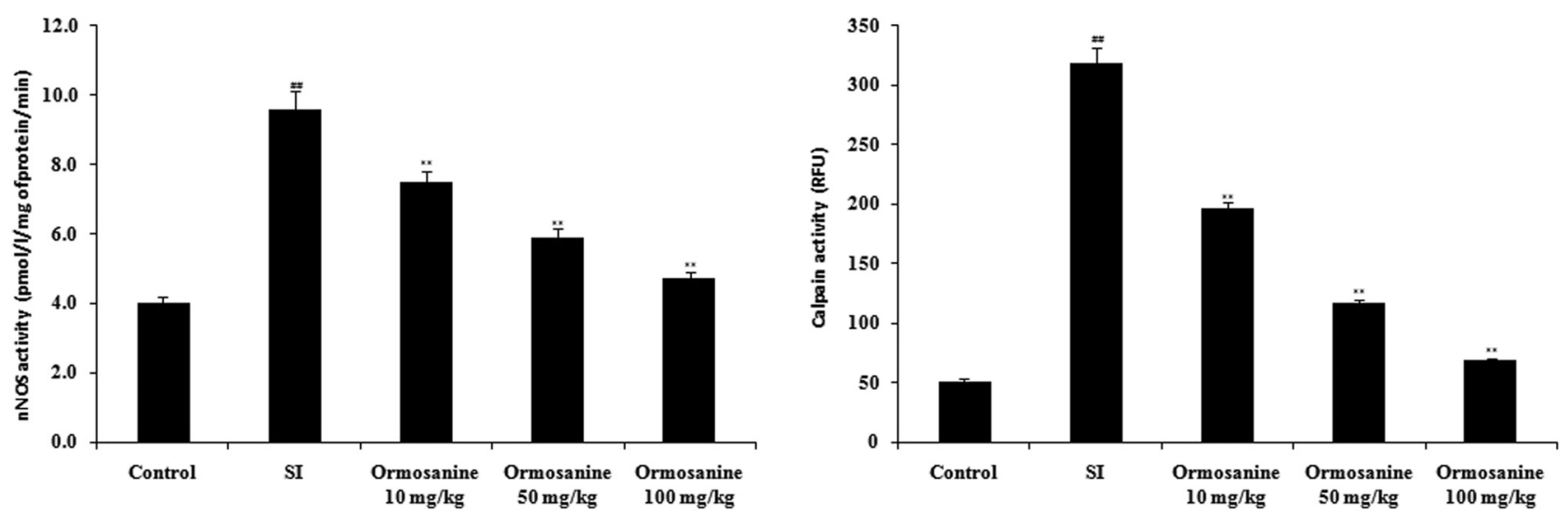

Figure 5: Ormosanine ameliorates the changes in activity of nNOS and calpain in the spinal tissue of $\mathrm{SCl}$ rats. Mean \pm SEM $(n=10)$. ${ }^{\# \#} P<0.01$ vs control group; ${ }^{\star \star} P<0.01$ vs $\mathrm{SCl}$ group.

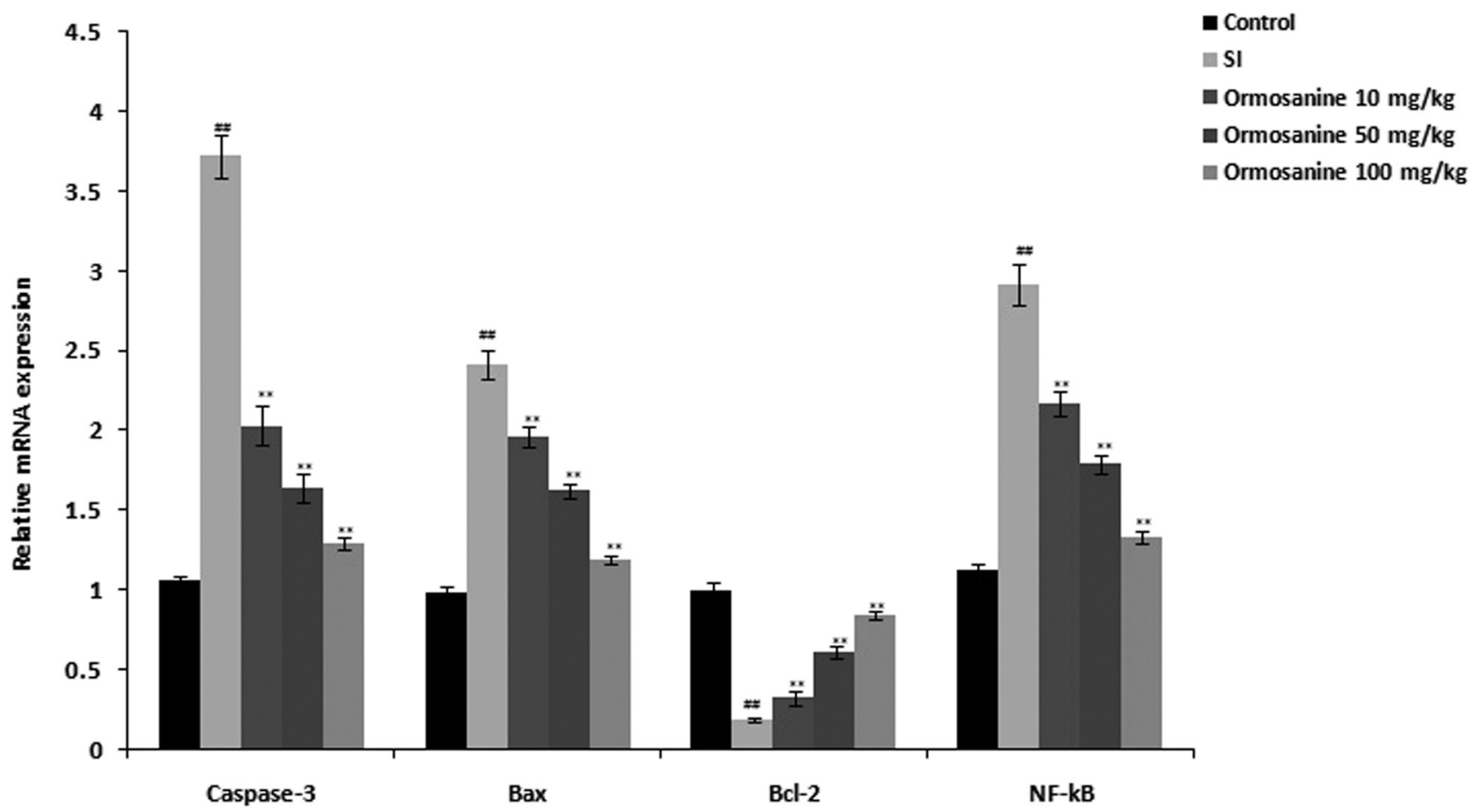

Figure 6: Effects of ormosanine on NF-kB, Caspase-3, Bax and Bcl2 mRNA expression in the spinal tissue of SCl rats. Mean \pm SEM $(n=10)$. ${ }^{\# \#} P<0.01$ vs control group; ${ }^{\star \star} P<0.01$ vs $\mathrm{SCl}$ group.

\subsection{Ormosanine ameliorates the changes in expression of nNOS, p-nNOS, calpain 1 and calpain 2 in the spinal tissue of $\mathrm{SCl}$ rats}

The levels of nNOS, calpain 1, calpain 2 and ERK protein expression were determined in the spinal tissue of ormosanine-treated SCI rats (Figure 7). The expression levels of nNOS, calpain 1 and calpain 2 protein were increased, and ERK protein expression was reduced in the spinal tissue of $\mathrm{SCI}$ rats. The changes in expression of nNOS, calpain 1, calpain 2 and ERK protein were ameliorated in the spinal tissue of the ormosanine treatment groups compared to the SCI group.

\subsection{Ormosanine ameliorates the pathological changes in the spinal tissue of $\mathrm{SCl}$ rats}

Nissl staining was performed to estimate the percentage of viable neurons in the spinal tissue of SCI rats by 

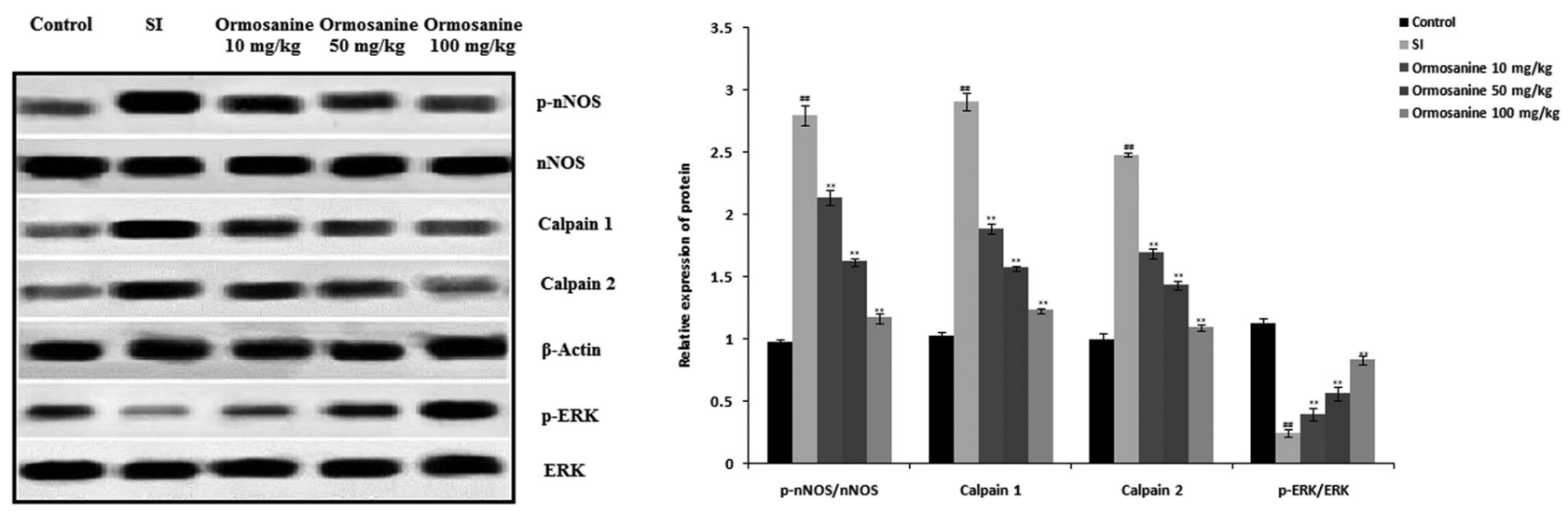

Figure 7: Effects of ormosanine on nNOS, ERK, calpain 1 and calpain 2 protein expression in the spinal tissue of $\mathrm{SCl}$ rats. Mean $\pm \mathrm{SEM}$ $(n=10) .{ }^{\# \#} P<0.01$ vs control group; ${ }^{\star \star} P<0.01$ vs $\mathrm{SCl}$ group.
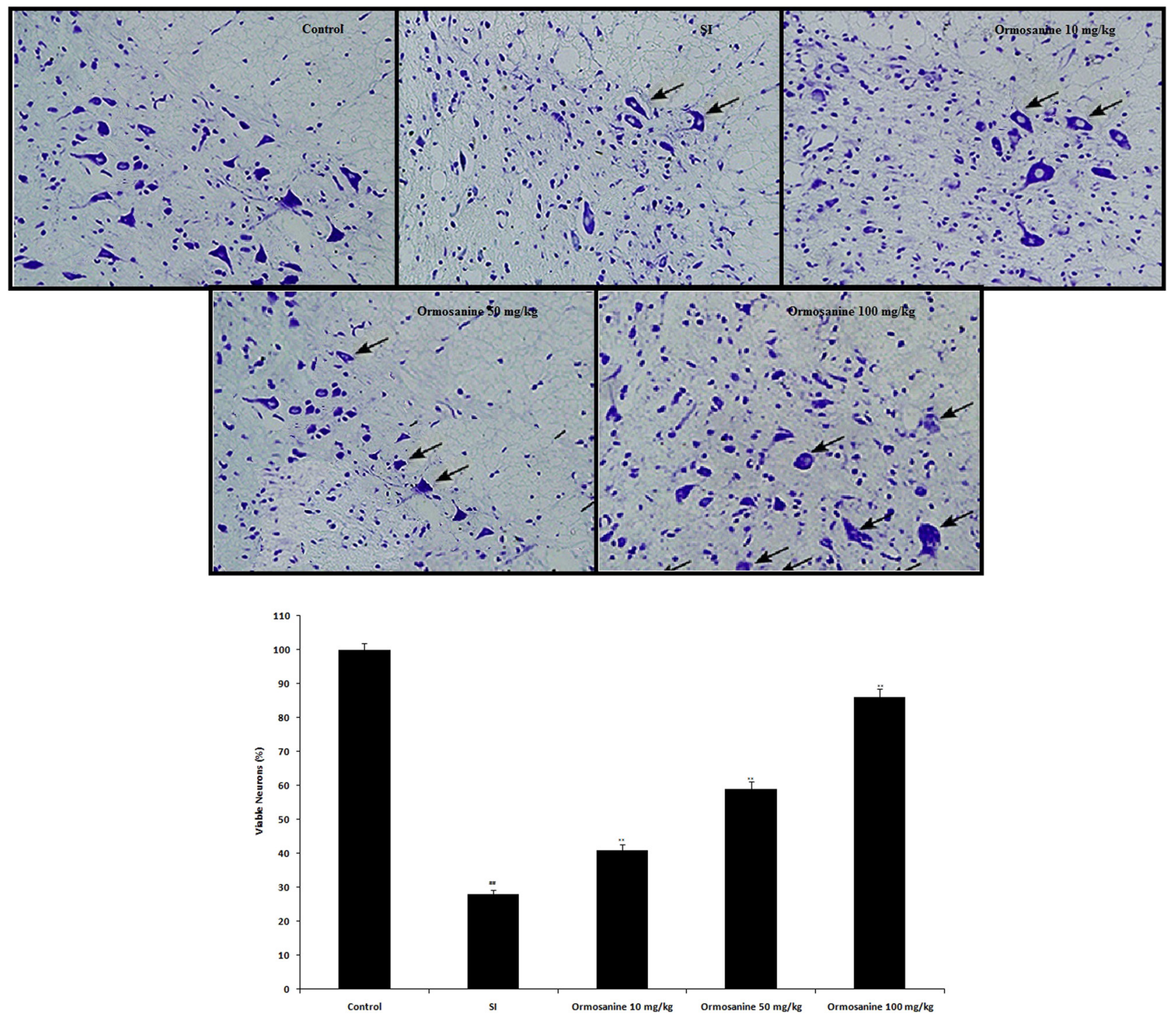

Figure 8: Effects of ormosanine on the percentage of viable neurons determined by Nissl staining in the spinal tissue of SCI rats. Mean \pm SEM $(n=10) .{ }^{\# \#} P<0.01$ vs control group; ${ }^{\star \star} P<0.01$ vs $\mathrm{SCl}$ group. 
histopathological analysis, as shown in Figure 8. The percentage of viable neurons was decreased in the SCI group compared to the control group. However, treatment with ormosanine ameliorated the change in the percentage of viable neurons in the spinal tissue of SCI rats.

\section{Discussion}

SCI is one of the major causes of permanent disability worldwide, including in China [18]. In SCI, neuronal injury occurs due to the progression of secondary injury, which involves several pathogenetic mechanisms [5], and novel treatments are required. The present study was performed to evaluate the effects of ormosanine in a rat SCI model by estimating neurological functions, such as pain threshold and locomotor function. The levels of cytokines, parameters of oxidative stress and production of ROS were examined in SCI rats. Moreover, calpain and NOS activities were determined, and quantitative reverse transcription polymerase chain reaction, Western blotting analysis and histopathological analysis were performed on the spinal tissue of SCI rats.

Secondary injury in SCI leads to activation of neuronal cell apoptosis due to enhanced release of inflammatory mediators, ischaemia, oedema and oxidative stress [19]. Primary injury in SCI enhances oxidative stress, which leads to increases in cytokine levels in the spinal tissue, resulting in the development of secondary injury [20]. Secondary injury in SCI occurs due to increased production of mitochondrial ROS, resulting in further secondary injury. The levels of cytokines, oxidative stress and ROS production were increased in the SCI group compared to the control group in the present study, and treatment with ormosanine ameliorated these effects. All of these alterations result in the progression of secondary neuronal injury, which further reduces the number of neurons by activation of neuronal apoptosis [21]. Ormosanine treatment was suggested to improve the number of viable neurons by reducing neuronal apoptosis, as it ameliorated the alterations in Caspase-3, Bax and Bcl2 mRNA expression in the spinal tissues of SCI rats. Caspase-3, Bax and Bcl2 proteins were reported to be involved in activation of the apoptosis pathway and were shown to stimulate apoptosis in SCI [22].

Activation of nNOS was reported to occur in the neuronal tissue following SCI, thus stimulating neuronal apoptosis; thus, inhibition of nNOS activity resulted in neuronal protection [23]. Moreover, nNOS-induced neuronal apoptosis in SCI causes neuronal degeneration by stimulating the activity of calpain [24]. Calpain inhibitor treatment or knockout was reported to prevent neuronal injury in SCI rats [25]. The findings of the present study supported these data and showed that treatment with ormosanine ameliorated the alterations in nNOS and calpain protein expression in the spinal tissue of SCI rats.

\section{Conclusion}

In conclusion, the results of the present study showed that ormosanine treatment protects against neuronal injury and reduces neuronal apoptosis in spinal cord-injured rats by regulating the peroxynitrite/calpain activity.

Acknowledgement: The authors are grateful to Beijing Jishuitan Hospital, China, for providing the necessary facilities to conduct this study.

Conflict of interest: The authors state no conflict of interest.

\section{References}

[1] Glass CK, Saijo K, Winner B, Marchetto MC, Gage FH. Mechanisms underlying inflammation in neurodegeneration. Cell. 2010;140(6):918-34.

[2] Singh A, Tetreault L, Kalsi-Ryan S, Nouri A, Fehlings MG. Global prevalence and incidence of traumatic spinal cord injury. Clin Epidemiol. 2014;6:309-31.

[3] Jones ZB, Ren Y. Sphingolipids in spinal cord injury. Int J Physiol Pathophysiol Pharmacol. 2016;8(2):52-69.

[4] Zhang N, Yin Y, Xu SJ, Wu YP, Chen WS. Inflammation and apoptosis in spinal cord injury. Indian J Med Res. 2012;135(3):287-96.

[5] Liu Z, Yao X, Jiang W, Li W, Zhu S, Liao C, et al. Advanced oxidation protein products induce microglia-mediated neuroinflammation via MAPKs-NF-KB signaling pathway and pyroptosis after secondary spinal cord injury. J Neuroinflammation. 2020;17(1):90.

[6] Wang JL, Luo X, Liu L. Targeting CARD6 attenuates spinal cord injury $(\mathrm{SCl})$ in mice through inhibiting apoptosis, inflammation and oxidative stress associated ROS production. Aging (Albany NY). 2019;11(24):12213-35.

[7] Alizadeh A, Dyck SM, Karimi-Abdolrezaee S. Traumatic spinal cord injury: an overview of pathophysiology, models and acute injury mechanisms. Front Neurol. 2019;10:282.

[8] Khan M, Singh I. Therapeutic exploitation of the S-nitrosoglutathione/S-nitrosylation mechanism for the treatment of contusion spinal cord injury. Neural Regen Res. 2019;14(6): 973-4. 
[9] Repair, protection and regeneration of spinal cord injury. Neural Regen Res. 2015;10(12):1953-75. doi: 10.4103/16735374.172314.

[10] Mimaki Y, Kuroda M, Yokosuka A, Harada H, Fukushima M, Sashida $Y$. Triterpenes and triterpene saponins from the stems of Akebia trifoliata. Chem Pharm Bull (Tokyo). 2003;51(8):960-5.

[11] Lee SH, Song YS, Jeong Y, Ko KS. Antioxidative and antiinflammatory activities of Akebia quinata extracts in an in vitro model of acute alcohol-induced hepatotoxicity. J Med Food. 2017;20(9):912-22.

[12] Ling Y, Zhang Q, Zhu DD, Chen F, Kong XH, Liao L. identification and characterization of the major chemical constituents in fructus Akebiae by high-performance liquid chromatography coupled with electrospray ionization-quadrupole-time-of-flight mass spectrometry. J Chromatogr Sci. 2016;54(2):148-57.

[13] Agra IK, Pires LL, Carvalho PS, Silva-Filho EA, Smaniotto S, Barreto E. Evaluation of wound healing and antimicrobial properties of aqueous extract from Bowdichia virgilioides stem barks in mice. Academia Brasileira de Ciências. 2013;85:945-54.

[14] Bhacca NS, Balandrin MF, Kinghorn AD, Frenkiel TA, Freeman R, Morris GA. Carbon-13 and proton two-dimensional NMR study of the Ormosia alkaloids panamine, ormosanine, and ormosinine. J Am Chem Soc. 1983;105:2538-44.

[15] Bravo JA, Lavaud C, Bourdy G, Deharo E, Gimenez A, Michel S. Antimalarial activity of ormosanine and hormoormosanine from Bowdichia virgiloides. Rev Boliviana de Quimica. 2002;2002(19):12-7.

[16] Seibenhener ML, Wooten MC. Use of the open field maze to measure locomotor and anxiety-like behavior in mice. J Vis Exp. 2015;(96):e52434.

[17] Ozawa A, Brunori G, Cippitelli A, Toll N, Schoch J, Kieffer BL, et al. Analysis of the distribution of spinal NOP receptors in a chronic pain model using NOP-eGFP knock-in mice. $\mathrm{Br}$ J Pharmacol. 2018;175(13):2662-75.

[18] Burns AS, O'Connell C. The challenge of spinal cord injury care in the developing world. J Spinal Cord Med. 2012;35(1):3-8.

[19] Jayaraj RL, Azimullah S, Beiram R, Jalal FY, Rosenberg GA. Neuroinflammation: friend and foe for ischemic stroke. J Neuroinflammation. 2019;16(1):142.

[20] Pavlova V, Filipova E, Uzunova K, Kalinov K, Vekov T. Pioglitazone therapy and fractures: systematic review and meta-analysis. Endocr Metab Immune Disord Drug Targets. 2018;18(5):502-7.

[21] Krishnamurthy K, Laskowitz DT. Cellular and molecular mechanisms of secondary neuronal injury following traumatic brain injury. In: Laskowitz D, Grant G, editors. Translational Research in Traumatic Brain Injury. Boca Raton (FL): CRC Press/Taylor and Francis Group; 2016, ch. 5.

[22] Papaliagkas V, Anogianaki A, Anogianakis G, Ilonidis G. The proteins and the mechanisms of apoptosis: a mini-review of the fundamentals. Hippokratia. 2007;11(3):108-13.

[23] Chang YW, Jakobi R, McGinty A, Foschi M, Dunn MJ, Sorokin A. Cyclooxygenase 2 promotes cell survival by stimulation of dynein light chain expression and inhibition of neuronal nitric oxide synthase activity. Mol Cell Biol. 2000;20(22):8571-9.

[24] Khan M, Dhammu TS, Matsuda F, Annamalai B, Dhindsa TS, Singh I, et al. Targeting the nNOS/peroxynitrite/calpain system to confer neuroprotection and aid functional recovery in a mouse model of TBI. Brain Res. 2016;1630: 159-70.

[25] Arataki S, Tomizawa K, Moriwaki A, et al. Calpain inhibitors prevent neuronal cell death and ameliorate motor disturbances after compression-induced spinal cord injury in rats. J Neurotrauma. 2005;22(3):398-406. 